\title{
ST-segment elevation myocardial infarction with non-chest pain presentation at the Emergency Department - Insights from the Singapore Myocardial Infarction Registry
}

Jeremy Zhenwen Pong ${ }^{1}$ (jeremypong@u.duke.nus.edu)

Andrew Fu Wah Ho ${ }^{2,3}$ (andrew.ho@mohh.com.sg)

Timothy Xin Zhong $\operatorname{Tan}^{4}$ (timothy.tbj13@gmail.com)

Huili Zheng ${ }^{5}$ (zheng huili@hpb.gov.sg)

Pin Pin Pek ${ }^{6}$ (pek.pin.pin@singhealth.com.sg)

Ching-Hui Sia7 (ching hui sia@nuhs.edu.sg)

Derek J Hausenloy,8,9,10,11,12 (derek.hausenloy@duke-nus.edu.sg)

Marcus Eng Hock Ong ${ }^{1,6,13^{*}}$ (marcus.ong.e.h@singhealth.com.sg)

${ }^{1}$ Duke-NUS Medical School, National University of Singapore, Singapore

2 SingHealth Duke-NUS Emergency Medicine Academic Clinical Programme

${ }^{3}$ Signature Programme in Cardiovascular \& Metabolic Disorders, Duke-NUS Medical School

${ }^{4}$ Emergency Medicine Residency Program, SingHealth Services, Singapore

${ }^{5}$ National Registry of Diseases Office, Health Promotion Board, Singapore

${ }^{6}$ Department of Emergency Medicine, Singapore General Hospital, Singapore

${ }^{7}$ Department of Cardiology, National University Heart Centre, Singapore

${ }^{8}$ National Heart Research Institute Singapore, National Heart Centre, Singapore

${ }^{9}$ Yong Loo Lin School of Medicine, National University of Singapore, Singapore

${ }^{10}$ The Hatter Cardiovascular Institute, University College London, London, UK

${ }^{11}$ The National Institute of Health Research University College London Hospitals Biomedical Research Centre, Research \& Development, London, UK

12 Tecnologico de Monterrey, Centro de Biotecnologia-FEMSA, Nuevo Leon, Mexico

${ }^{13}$ Health Service Research Centre, Singapore Health Services, Singapore

* Corresponding Author

Marcus Eng Hock Ong

Health Services Research Centre, Singapore Health Services

Academia, 20 College Road

Singapore 169856

Email: marcus.ong.e.h@singhealth.com.sg

\section{Funding acknowledgments}

DJH was supported by the British Heart Foundation (CS/14/3/31002), the National Institute for Health Research University College London Hospitals Biomedical Research Centre, DukeNational University Singapore Medical School, Singapore Ministry of Health's National Medical Research Council under its Clinician Scientist-Senior Investigator scheme 
(NMRC/CSA-SI/0011/2017) and Collaborative Centre Grant scheme (NMRC/CGAug16C006), and the Singapore Ministry of Education Academic Research Fund Tier 2 (MOE2016-T2-2-021). This article is based upon work from COST Action EU-CARDIOPROTECTION CA16225 supported by COST (European Cooperation in Science and Technology). 


\begin{abstract}
Background

ST-segment elevation myocardial infarction (STEMI) often presents acutely at the Emergency Department (ED). Although chest pain is a classical symptom, a significant proportion of patients do not present with chest pain. The impact of a non-chest pain (NCP) presentation on ED processes-of-care and outcomes is not fully understood. We utilised a national registry to characterise predictors, processes-of-care, and outcomes of NCP STEMI presentations.
\end{abstract}

\title{
Methods
}

Retrospective data for all STEMI cases occurring between 2010 to 2012 were analysed from the Singapore Myocardial Infarction Registry. Cases of inpatient onset, inter-facility transfers, and out-of-hospital cardiac arrests were excluded. Univariable analysis of demographic, clinical, processes-of-care, and outcome variables was conducted. Multivariable logistic regression ascertained independent predictors of a NCP presentation and 28-day mortality.

\section{Results}

Of 4667 STEMI cases, $12.9 \%$ presented without chest pain. Patients with NCP presentation were older (median, years $=74$ v. $58 ; p<0.001)$, more likely to be female $(39.1 \%$ v. $15.7 \%$; $p<0.001)$, of the Chinese race (72.5\% v. $62.7 \%$; $p<0.001)$, and with diabetes $(48.6 \%$ v. $36.7 \%$; $p<0.001)$. These patients were more likely to present with syncope $(6.0 \% \mathrm{v} .1 .9 \% ; p<0.001)$ or epigastric pain $(10.6 \%$ v. $4.9 \%$; $p<0.001)$. Patients with NCP presentation were less likely to receive percutaneous coronary intervention $(27.0 \%$ v. $75.6 \%$; $<<0.001)$, had longer door-toballoon time (median, minutes $=83$ v. $63 ; p<0.001$ ), and experienced greater mortality at 28 days (31.2\% v. 4.5\%; $p<0.001)$. On multivariable logistic regression, independent predictors of a NCP presentation included age (adjusted Odds Ratio [aOR] $=1.05,95 \%$ Confidence Interval [Cl] 1.04-1.07), diabetes (aOR=1.76, 95\% Cl 1.40-2.19), BMI (aOR=0.93, 95\% Cl 0.91-0.96), and dyslipidemia ( $\mathrm{aOR}=0.73,95 \% \mathrm{Cl} 0.58-0.91$ ). Absence of chest pain was an independent predictor for 28-day mortality (aOR=3.46, 95\% Cl 2.64-4.52).

\section{Conclusion}

Patients who presented with a NCP STEMI had a distinct clinical profile and experienced poorer outcomes. Routine triage ECG could be considered for patients with high-risk factors and non-classical symptoms. 


\section{Introduction}

Cardiovascular disease is implicated as the principal cause of death in Singapore and exerts substantial morbidity [1]. The proportion of cardiovascular diseases as a cause of death has risen from 6.3\% in the year 1950, to 31.3\% in the year 2017 [1]. Acute myocardial infarctions (AMI) are an important subset of cardiovascular disease, and can be classified as either a nonST-elevation myocardial infarction (NSTEMI) or a ST-elevation myocardial infarction (STEMI). In both instances, prompt recognition and treatment are crucial for optimal outcomes [2,3]. As many patients with AMI present emergently at the Emergency Department (ED), accurate diagnosis offers the opportunity for timely and appropriate intervention.

While chest pain is a classical symptom of AMI, a significant proportion of patients with AMI do not present with chest pain [4]. Studies have suggested that the prevalence of non-chest pain presentations exceeds $20 \%$ of all patients eventually diagnosed to have an AMI [5-8]. Such patients were found in previous studies to present instead with symptoms of dyspnea, diaphoresis, or syncope, and were typically women, patients of advanced age, and with comorbidities such as hypertension and diabetes mellitus [4-12]. Non-chest pain presentations of AMI have also been associated with delayed hospital presentation, less aggressive treatment, and increased mortality [6-8]. Previous studies have utilised different methods to define the population of patients who present atypically, with many defining them by the absence of pain in any body region $[11,13]$. This is opposed to the more clinically relevant absence of pain in the chest (non-chest pain STEMI presentation). As ED triage algorithms are predominantly chief complaint-oriented, and only certain chief complaints warrant a triage electrocardiogram (ECG), it is far more important to consider non-chest pain presentations of STEMI as a group. In addition, several studies that were done at a hospital or regional level may not have had the generalizability of results afforded by a national level registry [5-7,10-12].

We thus aim to characterise the presentations, predictors, processes-of-care, and outcomes of patients with STEMI who present without chest pain in Singapore, with a focus on patients who present at the ED. Data from a national AMI database will be utilised. 


\section{Methods}

\subsection{Study setting and design}

Singapore is a city-state with a total land area of $723 \mathrm{~km}^{2}$ and a population of 5.6 million people (population density: 7,800 people/ $\mathrm{km}^{2}$ ) [14]. Highly urbanized and interconnected, the nation is served by nine public and eight private hospitals equipped with modern emergency departments [15]. Emergency medical services (EMS) are managed by the Singapore Civil Defence Force (SCDF), a nation-wide centralised command that dispatches ambulances in response to calls made to an emergency hotline number. In $2017,88.9 \%$ of EMS calls were attended to within 11 minutes [16], with patients sent to the nearest public hospital. Between 2010 to 2012, 49.8\% of STEMI patients presented to the hospital via EMS [17].

Mandatory notification of all cases of $\mathrm{AMI}$ was enacted under the National Registry of Diseases Act for public hospitals in 2007, with extension to private hospitals in 2012 [18]. Reporting includes a small proportion of AMI cases occurring in homes that are certified by medical practitioners. Information for each case of AMI is collected and stored in the national level Singapore Myocardial Infarction Registry (SMIR), housed under the National Registry of Diseases Office (NRDO) [19].

\subsection{Study Population}

Sources of data utilised for AMI identification by the SMIR included inpatient discharge summaries, laboratory data, medical claims, and the national death registry [20]. For each case of AMI, registry coordinators extracted detailed patient data for entry into SMIR. Quality assurance included a logic check, where illogical data or outliers were flagged for review. Yearly internal audits were done to ensure inter-rater reliability of at least $95 \%$.

An AMI was defined as either a definitive AMI (definite ECG changes, or clinical symptoms and abnormal cardiac enzymes with probable ECG changes, or typical symptoms and abnormal cardiac enzymes where ECG was unavailable), clinical AMI (suggestive ECG changes of AMI but unsupported by typical symptoms or abnormal cardiac enzymes, or any two of the following three criteria: prolonged chest pain of more than 20 minutes, abnormal cardiac enzymes, or suggestive ECG changes), or death cases signed up with AMI as the cause of death [20]. Recurrence of AMI after 28 days of the initial event was counted as a separate episode in accordance with MONICA criteria [21]. STEMI was defined by typical chest pain lasting at least 20 minutes, accompanied by ST-elevation $(0.1$ or $0.2 \mathrm{mV}$ rise in two adjacent limb or precordial leads, or new left bundle branch block) and subsequently corroborated with raised cardiac enzymes.

\subsection{Selection of participants}

De-identified data of all cases of STEMI recorded in the SMIR between January 2010 to December 2012 were analysed. STEMI cases diagnosed between 2010 to 2011 were identified 
by International Classification of Diseases 9th Revision (ICD-9 Clinical Modification) code 410, while STEMI cases diagnosed in 2012 were identified by ICD-10 codes 121 and I22. Inpatient cases were excluded due to likely differences in etiology compared to cases presenting at the $E D$, with noncomparable process-of-care timings. Inter-facility transfers were similarly excluded for noncomparable process-of-care timings. As STEMIs resulting in out-of-hospital cardiac arrests would have different resuscitation and treatment priorities, they were also excluded from analysis.

\subsection{Statistical analysis}

Statistical analysis was performed using STATA SE (version 13) software. STEMI cases were classified into two comparator groups, those presenting with or without chest pain. We reported the baseline characteristics, clinical presentation, treatment received, process-ofcare timings, and patient outcomes. Continuous variables were presented as median (range) and compared between groups with the Mann-Whitney $U$ test, while categorical variables were presented as number (percentage) and compared between groups with the Pearson's chi-squared test or Fisher's exact test as appropriate. Multivariable logistic regression was conducted to ascertain independent variables predictive of a non-chest pain STEMI presentation, door-to-balloon time beyond 60 minutes, and death within 28 days from the onset of STEMI. All presenting variables relating to patient baseline characteristics and clinical parameters were initially included for multivariable analysis. Backward elimination of variables in a stepwise manner was subsequently performed to keep the multivariable models parsimonious. Statistical significance was set at a $p$-value $\leq 0.05$.

\subsection{Ethics approval}

This study was approved by SingHealth Centralised Institutional Review Board (CIRB Ref 2014/130/C) with a waiver of patient consent. 


\section{Results}

\subsection{Study population}

A total of 6412 cases of STEMI were identified. 1745 cases were excluded as they were interfacility transfers, inpatient-onset, or case leading to a cardiac arrest. Of the final 4667 cases, $603(12.9 \%)$ presented without chest pain. A population flow diagram is presented in Figure 1.

\subsection{Baseline demographics and clinical presentation}

Table 1 displays the demographic and clinical characteristics of the study population.

Patients without chest pain were almost two decades older (median age in years $=74$ v. 58 , $\mathrm{p}<0.001)$, more than twice as likely to be female (39.1\% v. $15.7 \%)$, and with higher rates of diabetes mellitus $(48.6 \%$ v. $36.7 \%, p<0.001)$. They also had an increased likelihood of having had a previous AMI $(18.2 \%$ v. $12.3 \%, \mathrm{p}<0.001)$, but were half as likely to have a previous history of coronary intervention (5.7\% v. $10.1 \%, p=0.001)$.

On presentation at the ED, patients without chest pain were three times as likely to present with syncope $(6.0 \%$ v. $1.9 \%, p<0.001)$, and twice as likely to present with epigastric pain $(10.6 \%$ v. $4.9 \%, p<0.001)$. They were less likely to present with textbook findings of dyspnea $(53.4 \%$ v. $60.2 \%, p=0.002)$, diaphoresis $(24.0 \%$ v. $69.3 \%, p<0.001)$, jaw pain $(0.8 \%$ v. $5.5 \%, p<0.001)$, or shoulder pain $(2.2 \%$ v. $6.6 \%, p<0.001)$. Killip scores for non-chest pain presentations were higher across all classes (class $1=62.9 \%$ v. $84.3 \%$; class $2=12.8 \%$ v. $6.7 \%$; class $3=12.1 \%$ v. $4.3 \%$; class $4=12.3 \%$ v. $4.8 \% ; p<0.001)$. Differences in rates of EMS utilization was not significant between groups (61.5\% v. $49.4 \%, p=0.144)$.

Patients without chest pain were more likely to have anterior STEMI $(57.5 \%$ v. $51.7 \%$, $p=0.008)$, lateral STEMI (39.5\% v. 35.0\%, p=0.033), and left bundle branch blocks ( $1.2 \%$ v. $0.2 \%$, $\mathrm{p}<0.001$ ) on ECG. Laboratory findings demonstrated non-chest pain STEMI patients to have lower hemoglobin (median hemoglobin in $\mathrm{g} / \mathrm{dL}=12.9 \mathrm{v} .14 .6, \mathrm{p}<0.001$ ), worse renal function (median creatinine in $\mu \mathrm{mol} / \mathrm{L}=109.0 \mathrm{v} .87 .0, \mathrm{p}<0.001$ ), and a more modest increase in cardiac enzymes as compared to chest pain presentations (peak troponin $\mathrm{T}$ in $\mu \mathrm{g} / \mathrm{L}=1.3 \mathrm{v} .3 .8$, $\mathrm{p}<0.001$; mean $\mathrm{CK}-\mathrm{MB}$ in $\mu \mathrm{g} / \mathrm{L}=15.4$ v. 70.5, $\mathrm{p}<0.001$ ) .

\subsection{Treatment received, process-of-care timings, and outcomes}

Table 2 displays the treatment received, process-of-care timings, and outcome variables of the study population.

Non-chest pain STEMI patients were less likely to receive goal-directed medical therapy. They were less likely to be started on aspirin $(98.2 \%$ v. $99.9 \%, p<0.001)$ or antiplatelet therapy $(96.4 \%$ v. $99.6 \%, p<0.001$ ) within the first 24 hours, and three times less likely to receive primary percutaneous coronary intervention $(27.0 \%$ v. $75.6 \%, p<0.001)$. The proportion of patients 
who achieved a door-to-balloon time under 90 minutes was decreased in the group that presented without chest pain $(60.1 \%$ v. $79.7 \%, p<0.001)$, although they had a shorter symptom-to-door timing (median time in minutes $=102$ v. $148, p<0.001$ ).

During their inpatient stay, patients with non-chest pain presentations were more likely to experience complications such as a complete heart block (4.6\% v. $2.7 \%, p=0.006)$, arrythmias (24.5\% v. 20.7\%, $p=0.025)$, acute renal failure ( $13.4 \%$ v. $3.7 \%, p<0.001)$, and left ventricular systolic dysfunction (73.7\% v. $61.7 \%, p<0.001)$. At 28 days following STEMI presentation at the ED, patients who did not have chest pain experienced seven times as much mortality $(31.2 \%$ v. $4.4 \%, p<0.001)$.

\subsection{Independent predictors of a non-chest pain STEMI presentation}

Table 3 displays variables predictive of a non-chest pain STEMI presentation. Adjusted positive predictors include an older age (adjusted Odds Ratio [aOR] $=1.05,95 \%$ Confidence Interval [Cl] 1.04 - 1.07), history of diabetes mellitus (aOR = 1.76, 95\% Cl $1.40-2.19$ ), worse renal function $(\mathrm{aOR}=1.01,95 \% \mathrm{Cl} 1.00-1.02)$, and higher Killip scores (class $2 \mathrm{aOR}=1.53,95 \%$ $\mathrm{Cl} 1.08$ - 2.16; class $3 \mathrm{aOR}=2.41,95 \% \mathrm{Cl} 1.69$ - 3.43; class 4 aOR $=2.50,95 \% \mathrm{Cl} 1.74-3.59$ ). Protective predictors included a higher body mass index (BMI) ( $\mathrm{aOR}=0.93,95 \% \mathrm{Cl} 0.91-0.96)$, presence of dyslipidemia ( $\mathrm{aOR}=0.73,95 \% \mathrm{Cl} 0.58-0.91)$, and increased hemoglobin $(\mathrm{aOR}=$ $0.91,95 \% \mathrm{Cl} 0.86-0.96)$.

\subsection{Independent predictors of 28-day mortality}

Table 4 displays the variables predictive of 28-day mortality. The absence of chest pain was three times as likely to lead to mortality $(\mathrm{aOR}=3.46,95 \% \mathrm{Cl} 2.64-4.52)$. These patients were also older $(\mathrm{aOR}=1.09,95 \% \mathrm{Cl} 1.08-1.10)$, with worse renal function $(\mathrm{aOR}=1.03,95 \% \mathrm{Cl} 1.03$ - 1.04), and with higher Killip scores (class $2 \mathrm{aOR}=1.24,95 \% \mathrm{Cl} 0.83-1.86$; class $4 \mathrm{aOR}=7.62$, $95 \% \mathrm{Cl} 5.32$ - 10.91). Among patients who underwent percutaneous coronary intervention, the absence of chest pain ( $\mathrm{aOR}=2.37,95 \% \mathrm{Cl} 1.59-3.53$ ) was an independent positive predictor of having a door-to-balloon time beyond 60 minutes (Supplementary table 1). 


\section{Discussion}

In this study, we utilised a national AMI registry to characterise STEMI patients who presented without chest pain. Patients who had a non-chest pain STEMI presentation were more likely to be older and with diabetes mellitus, and less likely to have an increased BMI or dyslipidemia. Severity of heart failure on presentation as classified by the Killip score was also increased. These patients were found to receive delayed and reduced rates of reperfusion therapy, and experienced poorer outcomes.

The prevalence of non-chest pain STEMI presentations in our population (12.9\%) was on the lower end of the spectrum as compared to previously reported prevalences of between $8.4 \%$ to $33 \%[4,6-8,22]$. This disparity could have arisen from population differences in ethnicity, comorbidities, and health seeking behaviour, which might in turn affect STEMI presentation. Differences may also have arisen from variability in study definitions and methodology.

When other demographic and clinical variables were controlled for, advanced age, diabetes mellitus as a comorbidity, raised serum creatinine, and an increased Killip score were found to be independent positive predictors of a non-chest pain STEMI presentation. The contribution of advanced age and diabetes mellitus toward a non-chest pain presentation is well documented in the literature [23], though its pathophysiology has not been well elucidated. Possible causes of a blunted pain perception include autonomic neuropathy, defective or inadequate stimulation of cardiac receptors, abnormalities in neuronal conduction, and neuropsychiatric factors [24-26]. With the prevalence of diabetes in Singapore projected to increase rapidly over the next few decades [27], STEMI diagnosis in the diabetic population would be made more challenging and would require a higher index of suspicion. The Killip score [28] was utilised in the ED to classify severity of presentation, and for prognostication. In our study, patients with more florid clinical signs of heart failure were more likely to have a non-chest pain STEMI presentation.

Independent negative predictors of a non-chest pain STEMI presentation were increased BMI, dyslipidemia as a comorbidity, and raised serum hemoglobin. The presence of increased BMI and dyslipidemia as negative predictors is intriguing, as these are conditions typically associated with a metabolic syndrome and neuropathy $[24,25]$ which may predispose instead to a non-chest pain presentation. There exists however the entity of an obesity paradox, which postulates that obesity, up to a certain point, may counterintuitively be protective against cardiovascular disease [29,30]. In a study of 19,499 elderly patients with STEMI, individuals of BMI 30.0 to 34.9 were found to experience the least mortality as compared to individuals with lower and higher BMIs [31]. This association between BMI and mortality has been corroborated by other studies [32]. Other authors have hypothesized that this phenomenon may instead be a "lean paradox", where normal or underweight individuals experience poorer outcomes due to a catabolic state and loss of lean mass [33]. As such, 
further detailed analysis on our dataset would be required to better understand the relationship between $\mathrm{BMI}$, dyslipidemia, and mortality in our population.

Although not found to be statistically significant on multivariable analysis, several variables that were associated with an increased likelihood for a non-chest pain STEMI were female gender, Chinese race, and STEMI location. The predisposition of females toward a non-chest pain STEMI presentation has been previously reported, with contributory factors ranging from an under-appreciation of cardiac symptoms by women [34], an increased likelihood of additional symptoms which delay diagnosis [34], and an often mistaken belief by physicians that AMIs are not common amongst women [24]. Differences in STEMI location on ECG diagnosis was also noted between groups, with anterior STEMIs, lateral STEMIs, and left bundle branch blocks occurring more frequently in patients who presented without chest pain. Although not conclusively associated, several studies have reported different symptomatic presentations as influenced by the location of infarction $[35,36]$. Interestingly, rates of EMS utilization were not significantly different between STEMI patients who presented with or without chest pain.

There are several strengths of our study. To the best of our knowledge, the issue of non-chest pain presentation of STEMI has not been studied in a national database. We do acknowledge several limitations. The poorer outcomes experienced by a non-chest pain STEMI presentation could have been influenced by delayed diagnosis and treatment. The SMIR however does not collect other process-of-care timings such as time taken from presentation to physician consult, or time taken from presentation to ECG diagnosis, that might better explain the reasons for treatment delay. These specific findings may need to be explored in further studies. Results may have been influenced by survivor bias, as patients who progressed to cardiac arrests were excluded from analysis. This may not be relevant however, as patients who had a cardiac arrest would be recommended to have emergency $\mathrm{PCl}$ and have different process-of-care timings. Our study utilized data from 2010 to 2012 which represented a time lag of several years. This was due to limitations to data access, and further studies are thus needed to examine trends in non-chest pain STEMI presentations as they evolve over the years. Although mandatory notification of STEMI cases occurring in private hospitals was enacted only from 2012 onwards, we believe that the non-mandatory contribution of data from private hospitals to have a small effect on the validity of the study. Public sector healthcare encompasses an overwhelming majority of all hospital care provided in Singapore, with public cases comprising nearly $98 \%$ of all cases in the SMIR [17].

A practical application from this study could be to conduct routine ECG readings for patients who have a high-risk profile for a non-chest pain STEMI presentation. For instance, all elderly female diabetics, with symptoms of dyspnea, diaphoresis, epigastric pain, or syncope. Doctors and nurses can be trained to better identify high-risk patients, and have a lower threshold for ordering an ECG should they suspect a non-chest pain STEMI presentation. Public education 
should be extended to the population-at-risk to educate them on non-chest pain presentations of STEMI, with counselling to seek prompt medical assistance. 


\section{Conclusion}

Patients who presented with a non-chest pain STEMI had a distinct clinical profile, were often misdiagnosed, undertreated, and experienced poorer outcomes. Routine triage ECG could be considered for patients with high-risk factors and non-classical symptoms. 


\section{References}

1. Ministry of Health Singapore. Total deaths by broad causes.

https://www.moh.gov.sg/resources-statistics/singapore-health-facts/principal-causes-ofdeath. Accessed 27 December 2018.

2. Steg, P.G.; James, S.K.; Atar, D., et al. ESC Guidelines for the management of acute myocardial infarction in patients presenting with ST-segment elevation. European heart journal 2012, 33 (20), pp. 2569-619.

3. Yadlapati, A.; Gajjar, M.; Schimmel, D.R., et al. Contemporary management of STsegment elevation myocardial infarction. Internal and emergency medicine 2016, 11 (8), pp. 1107-13.

4. Brieger, D.; Eagle, K.A.; Goodman, S.G., et al. Acute coronary syndromes without chest pain, an underdiagnosed and undertreated high-risk group: insights from the Global Registry of Acute Coronary Events. Chest 2004, 126 (2), pp. 461-9.

5. Sigurdsson, E.; Thorgeirsson, G.; Sigvaldason, H., et al. Unrecognized myocardial infarction: epidemiology, clinical characteristics, and the prognostic role of angina pectoris. The Reykjavik Study. Ann Intern Med 1995, 122 (2), pp. 96-102.

6. Dorsch, M.F.; Lawrance, R.A.; Sapsford, R.J., et al. Poor prognosis of patients presenting with symptomatic myocardial infarction but without chest pain. Heart (British Cardiac Society) 2001, 86 (5), pp. 494-8.

7. Uretsky, B.F.; Farquhar, D.S.; Berezin, A.F., et al. Symptomatic myocardial infarction without chest pain: prevalence and clinical course. The American journal of cardiology 1977, 40 (4), pp. 498-503.

8. Canto, J.G.; Shlipak, M.G.; Rogers, W.J., et al. Prevalence, clinical characteristics, and mortality among patients with myocardial infarction presenting without chest pain. Jama 2000, 283 (24), pp. 3223-9.

9. Gregoratos, G. Clinical manifestations of acute myocardial infarction in older patients. The American journal of geriatric cardiology 2001, 10 (6), pp. 345-7.

10. Calle, P.; Jordaens, L.; De Buyzere, M., et al. Age-related differences in presentation, treatment and outcome of acute myocardial infarction. Cardiology 1994, 85 (2), pp. 111-20.

11. Culic, V.; Eterovic, D.; Miric, D., et al. Symptom presentation of acute myocardial infarction: influence of sex, age, and risk factors. American heart journal 2002, 144 (6), pp. 1012-7.

12. Grosmaitre, P.; Le Vavasseur, O.; Yachouh, E., et al. Significance of atypical symptoms for the diagnosis and management of myocardial infarction in elderly patients admitted to emergency departments. Archives of cardiovascular diseases 2013, 106 (11), pp. 586-92.

13. Pek, P.P.; Loy, E.Y.; Wah, W., et al. Reperfusion treatment delays amongst patients with painless ST segment elevation myocardial infarction. Cjem 2017, 19 (5), pp. 355-63.

14. Department of Statistics, S.G. Population and Population Structure.

https://www.singstat.gov.sg/find-data/search-by-theme/population/population-andpopulation-structure/latest-data. Accessed 31 December 2018.

15. Ministry of Health Singapore. Health Facilities. https://www.moh.gov.sg/resourcesstatistics/singapore-health-facts/health-facilities. Accessed 31 December 2018.

16. Singapore Civil Defense Force. Fire, Ambulance and Enforcement statistics 2017. https://www.scdf.gov.sg/docs/default-source/scdf-library/publications/amb-fire-inspectionstatistics/fire-ambulance-enforcement-statistics-2017.pdf. Accessed 31 December 2018. 
17. Ho, A.F.; Loy, E.Y.; Pek, P.P., et al. Emergency Medical Services Utilization among Patients with ST-Segment Elevation Myocardial Infarction: Observations from the Singapore Myocardial Infarction Registry. Prehospital emergency care : official journal of the National Association of EMS Physicians and the National Association of State EMS Directors 2016, 20 (4), pp. 454-61.

18. Singapore Attorney General's Chambers. National Registry of Diseases Act. https://sso.agc.gov.sg/Act/NRDA2007. Accessed 31 December 2018.

19. National Registry of Diseases Office. Singapore Myocardial Infarction Registry. https://www.nrdo.gov.sg/publications/ami. Accessed 31 December 2018.

20. National Registry of Diseases Office. Trends in Acute Myocardial Infarction in Singapore 2007-2012. https://www.nrdo.gov.sg/docs/librariesprovider3/Publications--AMI/sinmyocardinfreg2007-2012.pdf?sfvrsn=0\&AspxAutoDetectCookieSupport=1. Accessed 31 December 2018.

21. The World Health Organization MONICA Project (monitoring trends and determinants in cardiovascular disease): a major international collaboration. WHO MONICA Project Principal Investigators. Journal of clinical epidemiology 1988, 41 (2), pp. 105-14. 22. Cho, J.Y.; Jeong, M.H.; Ahn, Y.K., et al. Comparison of outcomes of patients with painless versus painful ST-segment elevation myocardial infarction undergoing percutaneous coronary intervention. The American journal of cardiology 2012, 109 (3), pp. 337-43.

23. Valensi, P.; Lorgis, L., Cottin, Y. Prevalence, incidence, predictive factors and prognosis of silent myocardial infarction: a review of the literature. Archives of cardiovascular diseases 2011, 104 (3), pp. 178-88.

24. Sheifer, S.E.; Manolio, T.A., Gersh, B.J. Unrecognized myocardial infarction. Ann Intern Med 2001, 135 (9), pp. 801-11.

25. Langer, A.; Freeman, M.R.; Josse, R.G., et al. Detection of silent myocardial ischemia in diabetes mellitus. The American journal of cardiology 1991, 67 (13), pp. 1073-8.

26. Nadelmann, J.; Frishman, W.H.; Ooi, W.L., et al. Prevalence, incidence and prognosis of recognized and unrecognized myocardial infarction in persons aged 75 years or older: The Bronx Aging Study. The American journal of cardiology 1990, 66 (5), pp. 533-7.

27. Phan, T.P.; Alkema, L.; Tai, E.S., et al. Forecasting the burden of type 2 diabetes in Singapore using a demographic epidemiological model of Singapore. BMJ Open Diabetes Res Care 2014, (2052-4897 (Print)), pp.

28. Killip, T., 3rd, Kimball, J.T. Treatment of myocardial infarction in a coronary care unit. A two year experience with 250 patients. The American journal of cardiology 1967, 20 (4), pp. 457-64.

29. Hainer, V., Aldhoon-Hainerova, I. Obesity paradox does exist. Diabetes care 2013, 36 Suppl 2, pp. S276-81.

30. Niedziela, J.; Hudzik, B.; Niedziela, N., et al. The obesity paradox in acute coronary syndrome: a meta-analysis. European journal of epidemiology 2014, 29 (11), pp. 801-12.

31. Neeland, I.J.; Das, S.R.; Simon, D.N., et al. The obesity paradox, extreme obesity, and long-term outcomes in older adults with ST-segment elevation myocardial infarction: results from the NCDR. European heart journal Quality of care \& clinical outcomes 2017, 3 (3), pp. 183-91.

32. Allahwala, U.; Hoo, S.S.; Figtree, G., et al. The "Obesity Paradox" in a Contemporary ST Elevation Myocardial Infarction (STEMI) Cohort. Heart, Lung and Circulation 2016, 25, pp. S322. 
33. Elagizi, A.; Kachur, S.; Lavie, C.J., et al. An Overview and Update on Obesity and the Obesity Paradox in Cardiovascular Diseases. Progress in cardiovascular diseases 2018, 61 (2), pp. 142-50.

34. de Torbal, A.; Boersma, E.; Kors, J.A., et al. Incidence of recognized and unrecognized myocardial infarction in men and women aged 55 and older: the Rotterdam Study.

European heart journal 2006, 27 (6), pp. 729-36.

35. Culic, V.; Miric, D., Eterovic, D. Correlation between symptomatology and site of acute myocardial infarction. International journal of cardiology 2001, 77 (2-3), pp. 163-8. 36. Lichstein, E.; Breitbart, S.; Shani, J., et al. Relationship between location of chest pain and site of coronary artery occlusion. American heart journal 1988, 115 (3), pp. 564-8. 
Tables and Figures

Table 1: Baseline characteristics and clinical parameters amongst patients with STEMI.

\begin{tabular}{|c|c|c|c|}
\hline & $\begin{array}{l}\text { Chest pain } \\
n=4064(87.1 \%)\end{array}$ & $\begin{array}{l}\text { No chest pain } \\
n=603(12.9 \%)\end{array}$ & P-value \\
\hline Age in years, median (range)* & $58(21-102)$ & $74(21-100)$ & $<0.001$ \\
\hline Gender, $\mathrm{n}(\%)^{*}$ & & & $<0.001$ \\
\hline Male & $3427(84.3)$ & $367(60.9)$ & \\
\hline Female & $637(15.7)$ & $236(39.1)$ & \\
\hline Race, n (\%)* & & & $<0.001$ \\
\hline Chinese & $2550(62.7)$ & $437(72.5)$ & \\
\hline Malay & $848(20.9)$ & $105(17.4)$ & \\
\hline Indian & 606 (14.9) & $53(8.8)$ & \\
\hline Others & $60(1.5)$ & $8(1.3)$ & \\
\hline $\mathrm{BMI}$ in $\mathrm{kg} / \mathrm{m}^{2}$, median (range)* & $24.5(12.6-47.1)$ & $22.3(12.3-43.4)$ & $<0.001$ \\
\hline Smoking status, $\mathrm{n}(\%)^{*}$ & & & $<0.001$ \\
\hline Current & $1978(49.0)$ & $141(24.5)$ & \\
\hline Ex-smoker & $558(13.8)$ & $92(16.0)$ & \\
\hline Never & $1500(37.2)$ & $342(59.5)$ & \\
\hline \multicolumn{4}{|l|}{ Past medical history, $\mathrm{n}(\%)$} \\
\hline Hypertension* & $2212(54.5)$ & $413(68.9)$ & $<0.001$ \\
\hline Diabetes mellitus* & $1491(36.7)$ & $291(48.6)$ & $<0.001$ \\
\hline Dyslipidemia* & $2549(62.8)$ & $331(55.3)$ & $<0.001$ \\
\hline AMI* & $501(12.3)$ & $109(18.2)$ & $<0.001$ \\
\hline CABG & $61(1.5)$ & $6(1.0)$ & 0.338 \\
\hline PTCA/PCI* & $408(10.1)$ & $34(5.7)$ & 0.001 \\
\hline EMS utilisation, n (\%) & $2007(49.4)$ & $371(61.5)$ & 0.144 \\
\hline \multicolumn{4}{|l|}{ Presenting symptoms, n (\%) } \\
\hline Dyspnea* & $2446(60.2)$ & $322(53.4)$ & 0.002 \\
\hline Diaphoresis* & $2818(69.3)$ & $145(24.0)$ & $<0.001$ \\
\hline Syncope* & 77 (1.9) & $36(6.0)$ & $<0.001$ \\
\hline Back pain* & $356(8.8)$ & $27(4.5)$ & $<0.001$ \\
\hline Epigastric pain* & $198(4.9)$ & $64(10.6)$ & $<0.001$ \\
\hline Jaw pain* & $222(5.5)$ & $5(0.8)$ & $<0.001$ \\
\hline Shoulder pain* & $269(6.6)$ & $13(2.2)$ & $<0.001$ \\
\hline \multicolumn{4}{|l|}{ ECG diagnosis, $\mathrm{n}(\%)$} \\
\hline Anterior* & $2102(51.7)$ & $347(57.5)$ & 0.008 \\
\hline Posterior* & $513(12.6)$ & $53(8.8)$ & 0.007 \\
\hline Inferior* & $1841(45.3)$ & $222(36.8)$ & $<0.001$ \\
\hline Lateral* & $1423(35.0)$ & $238(39.5)$ & 0.033 \\
\hline LBBB* & $8(0.2)$ & $7(1.2)$ & $<0.001$ \\
\hline Right ventricular & $227(5.6)$ & $28(4.6)$ & 0.342 \\
\hline \multicolumn{4}{|l|}{ Cardiac enzymes, median (range) ${ }^{\dagger}$} \\
\hline Peak troponin $\mathrm{T}$ in $\mu \mathrm{g} / \mathrm{L}^{*}$ & $3.8(0.003-60.4)$ & $1.3(0.006-90.0)$ & $<0.001$ \\
\hline
\end{tabular}




\begin{tabular}{llll} 
Mean CK-MB in $\mu \mathrm{g} / \mathrm{L}^{*}$ & $70.5(0.7-1000.0)$ & $15.4(1.0-509.8)$ & $<0.001$ \\
Creatinine in $\mu \mathrm{mol} / \mathrm{L}$, median (range)* & $87.0(12.0-1348.0)$ & $109.0(24.0-1537.0)$ & $<0.001$ \\
Hemoglobin in $\mathrm{g} / \mathrm{dL}$, median (range)* & $14.6(4.5-20.0)$ & $12.9(5.3-19.1)$ & $<0.001$ \\
Killip score, $\mathrm{n}(\%)^{*}$ & & & $<0.001$ \\
Class 1 & $3426(84.3)$ & $379(62.9)$ & \\
Class 2 & $271(6.7)$ & $77(12.8)$ & \\
Class 3 & $173(4.3)$ & $73(12.1)$ & \\
Class 4 & $194(4.8)$ & $74(12.3)$ & \\
\hline
\end{tabular}

AMI: Acute myocardial infarction; BMI: Body mass index; CABG: Coronary artery bypass grafting; CK-MB: Creatine kinase - muscle/brain; ECG: Electrocardiogram; EMS: Emergency medical services; LBBB: Left bundle branch block; $\mathrm{PCl}$ : Percutaneous coronary intervention; PTCA: Percutaneous transluminal coronary angioplasty; STEMI: ST-elevation myocardial infarction.

${ }^{\dagger}$ Includes a maximum of five readings taken within 72-hours of STEMI diagnosis.

* Variables that are statistically different between the two groups ( $P$-value $\leq 0.05)$.

Table 2: Treatment characteristics, process-of-care timings, and clinical outcomes amongst patients with STEMI.

\begin{tabular}{|c|c|c|c|}
\hline & $\begin{array}{l}\text { Chest pain } \\
n=4064 \\
(87.1 \%) \\
\end{array}$ & $\begin{array}{l}\text { No chest pain } \\
n=603 \\
(12.9 \%)\end{array}$ & P-value \\
\hline \multicolumn{4}{|l|}{ Medications within $24 \mathrm{~h}, \mathrm{n}(\%)^{+}$} \\
\hline Aspirin* & 3921 (99.9) & $483(98.2)$ & $<0.001$ \\
\hline Antiplatelet* & $3986(99.6)$ & $458(96.4)$ & $<0.001$ \\
\hline Beta-blockers & $2423(96.3)$ & $205(94.0)$ & 0.103 \\
\hline \multicolumn{4}{|l|}{ Reperfusion, n (\%) } \\
\hline Primary $\mathrm{PCl}^{*}$ & $3073(75.6)$ & $163(27.0)$ & $<0.001$ \\
\hline Urgent CABG & $4(0.1)$ & $1(0.2)$ & 0.499 \\
\hline \multicolumn{4}{|l|}{ Process-of-care-timings in minutes ${ }^{\dagger}$} \\
\hline Symptom-to-door time, median (range)* & $148(0-10556)$ & $102(10-7602)$ & $<0.001$ \\
\hline Door-to-balloon time, median (range)* & $63(9-1641)$ & $83(29-1559)$ & $<0.001$ \\
\hline Symptom-to-balloon, median (range) & $204(43-4643)$ & $225(78-1991)$ & 0.806 \\
\hline Door-to-balloon time $\leq 60 \mathrm{~min}, \mathrm{n}(\%)^{*}$ & $1378(44.8)$ & $36(22.1)$ & $<0.001$ \\
\hline Door-to-balloon time $\leq 90 \mathrm{~min}, \mathrm{n}(\%)^{*}$ & $2448(79.7)$ & $98(60.1)$ & $<0.001$ \\
\hline \multicolumn{4}{|l|}{ Inpatient events, $\mathrm{n}(\%)^{\dagger}$} \\
\hline Complete heart block* & $108(2.7)$ & $28(4.6)$ & 0.006 \\
\hline Arrhythmia* & $840(20.7)$ & $148(24.5)$ & 0.025 \\
\hline Acute renal failure* & $151(3.7)$ & $81(13.4)$ & $<0.001$ \\
\hline Stroke & $38(0.9)$ & $8(1.3)$ & 0.356 \\
\hline LVSD* & 2367 (61.7) & $337(73.7)$ & $<0.001$ \\
\hline 28-day mortality, n (\%)* & $180(4.4)$ & $188(31.2)$ & $<0.001$ \\
\hline Cause of death, n (\%) & & & 0.323 \\
\hline
\end{tabular}


AMI

$124(68.9)$

$121(64.4)$

Non-AMI

$53(29.4)$

$66(35.1)$

Unknown

$3(1.7)$

$1(0.5)$

AMI: Acute myocardial infarction; CABG: Coronary artery bypass grafting; LVSD: Left ventricular systolic dysfunction; PCl: Percutaneous coronary intervention, STEMI: STelevation myocardial infarction.

+ Patients with contraindications or whom the variable was not applicable to were excluded from the calculation of percentages.

* Variables that are statistically different between the two groups ( $P$-value $\leq 0.05$ ).

Table 3: Independent predictors of a non-chest pain STEMI presentation amongst patients with STEMI.

Unadjusted OR (95\% Cl) Adjusted OR (95\% Cl)

\begin{tabular}{|c|c|c|}
\hline Age & $1.08(1.08-1.09)$ & $1.05(1.04-1.07)$ \\
\hline \multicolumn{3}{|l|}{ Gender } \\
\hline Male & 1.00 (reference) & - \\
\hline Female & $3.46(2.88-4.16)$ & - \\
\hline \multicolumn{3}{|l|}{ Race } \\
\hline Chinese & 1.00 (reference) & - \\
\hline Malay & $0.72(0.58-0.91)$ & - \\
\hline Indian & $0.51(0.38-0.69)$ & - \\
\hline Others & $0.78(0.37-1.64)$ & - \\
\hline BMI & $0.87(0.84-0.89)$ & $0.93(0.91-0.96)$ \\
\hline \multicolumn{3}{|l|}{ Smoking status } \\
\hline Current & 1.00 (reference) & - \\
\hline Ex-smoker & $2.31(1.75-3.06)$ & - \\
\hline Never & $3.20(2.60-3.94)$ & - \\
\hline \multicolumn{3}{|l|}{ Past medical history } \\
\hline Hypertension & $1.85(1.54-2.23)$ & - \\
\hline Diabetes mellitus & $1.63(1.37-1.93)$ & $1.76(1.40-2.19)$ \\
\hline Dyslipidemia & $0.73(0.62-0.87)$ & $0.73(0.58-0.91)$ \\
\hline $\mathrm{AMI} / \mathrm{CABG} / \mathrm{PCl}$ & $1.54(1.22-1.93)$ & - \\
\hline \multicolumn{3}{|l|}{ ECG diagnosis } \\
\hline Anterior & $1.27(1.06-1.50)$ & - \\
\hline Posterior & $0.67(0.50-0.90)$ & - \\
\hline Inferior & $0.70(0.59-0.84)$ & - \\
\hline Lateral & $1.21(1.02-1.44)$ & - \\
\hline LBBB & $5.95(2.15-16.48)$ & - \\
\hline Right ventricular & $0.82(0.55-1.23)$ & - \\
\hline Creatinine & $1.04(1.03-1.05)$ & $1.01(1.00-1.02)$ \\
\hline Hemoglobin & $0.69(0.67-0.72)$ & $0.91(0.86-0.96)$ \\
\hline
\end{tabular}


Killip score

Class 1

1.00 (reference)

1.00 (reference)

Class 2

2.57 (1.95 - 3.38)

1.53 (1.08 - 2.16)

Class 3

3.81 (2.84 - 5.12)

2.41 (1.69 - 3.43)

Class 4

3.45 (2.59- 4.60)

2.50 (1.74 - 3.59)

AMI: Acute myocardial infarction; BMI: Body mass index; CABG: Coronary artery bypass grafting; Cl: Confidence interval; ECG: Electrocardiogram; LBBB: Left bundle branch block; OR: Odds ratio; $\mathrm{PCl}$ : Percutaneous coronary intervention; STEMI: ST-elevation myocardial infarction.

Table 4: Independent predictors of 28-day mortality amongst patients with STEMI.

Unadjusted OR (95\% Cl) $\quad$ Adjusted OR (95\% Cl)

\begin{tabular}{|c|c|c|}
\hline No chest pain & $9.77(7.78-12.28)$ & $3.46(2.64-4.52)$ \\
\hline Age & $1.11(1.10-1.12)$ & $1.09(1.08-1.10)$ \\
\hline \multicolumn{3}{|l|}{ Gender } \\
\hline Male & 1.00 (reference) & - \\
\hline Female & $4.02(3.22-5.01)$ & - \\
\hline \multicolumn{3}{|l|}{ Race } \\
\hline Chinese & 1.00 (reference) & - \\
\hline Malay & $0.88(0.67-1.15)$ & - \\
\hline Indian & $0.42(0.28-0.64)$ & - \\
\hline Others & $0.48(0.15-1.53)$ & - \\
\hline BMI & $0.86(0.83-0.89)$ & - \\
\hline \multicolumn{3}{|l|}{ Smoking status } \\
\hline Current & 1.00 (reference) & - \\
\hline Ex-smoker & $3.81(2.66-5.47)$ & - \\
\hline Never & $4.22(3.15-5.66)$ & - \\
\hline \multicolumn{3}{|l|}{ Past medical history } \\
\hline Hypertension & $1.80(1.43-2.27)$ & - \\
\hline Diabetes mellitus & $1.30(1.05-1.61)$ & - \\
\hline Dyslipidemia & $0.59(0.48-0.73)$ & - \\
\hline $\mathrm{AMI} / \mathrm{CABG} / \mathrm{PCl}$ & $1.46(1.10-1.93)$ & - \\
\hline \multicolumn{3}{|l|}{ ECG diagnosis } \\
\hline Anterior & $1.19(0.96-1.48)$ & $0.69(0.43-1.10)$ \\
\hline Posterior & $0.72(0.50-1.04)$ & - \\
\hline Inferior & $0.69(0.56-0.87)$ & $0.63(0.39-1.02)$ \\
\hline Lateral & $1.24(1.00-1.54)$ & - \\
\hline LBBB & $5.91(2.01-17.38)$ & - \\
\hline Right ventricular & $0.56(0.31-1.01)$ & $0.39(0.19-0.80)$ \\
\hline Creatinine & $1.05(1.04-1.06)$ & $1.03(1.03-1.04)$ \\
\hline Hemoglobin & $0.67(0.64-0.70)$ & - \\
\hline
\end{tabular}


Killip score

Class 1

1.00 (reference)

1.00 (reference)

Class 2

2.64 (1.87-3.72)

1.24 (0.83 - 1.86)

Class 3

2.75 (1.86-4.07)

$0.89(0.57-1.41)$

Class 4

8.53 (6.37-11.42)

7.62 (5.32 - 10.91)

AMI: Acute myocardial infarction; BMI: Body mass index; CABG: Coronary artery bypass grafting; Cl: Confidence interval; ECG: Electrocardiogram; LBBB: Left bundle branch block; OR: Odds ratio; $\mathrm{PCl}$ : Percutaneous coronary intervention; STEMI: ST-elevation myocardial infarction.

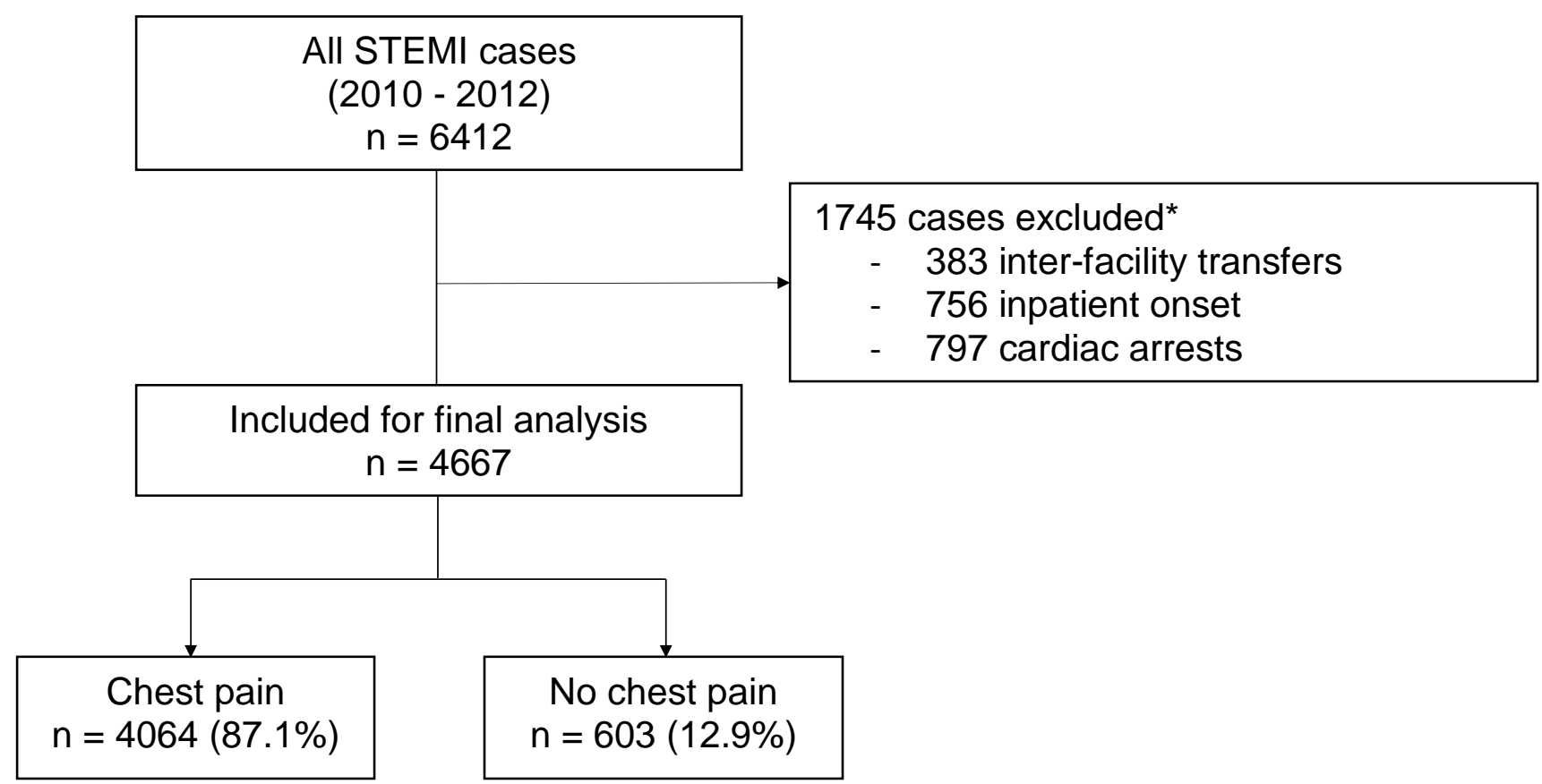

Figure 1. Population flow diagram. STEMI: ST-elevation myocardial infarction.

* Cases are not mutually exclusive. 


\section{Supplementary data}

Supplementary table 1: Independent predictors of door-to-balloon time more than 60 minutes amongst patients with STEMI who had PCI.

\begin{tabular}{|c|c|c|}
\hline & Unadjusted OR (95\% Cl) & Adjusted OR $(95 \% \mathrm{Cl})$ \\
\hline No chest pain & $2.87(1.97-4.18)$ & $2.37(1.59-3.53)$ \\
\hline Age & $1.02(1.01-1.02)$ & - \\
\hline \multicolumn{3}{|l|}{ Gender } \\
\hline Male & 1.00 (reference) & 1.00 (reference) \\
\hline Female & $2.14(1.72-2.68)$ & $2.06(1.64-2.60)$ \\
\hline \multicolumn{3}{|l|}{ Race } \\
\hline Chinese & 1.00 (reference) & - \\
\hline Malay & $1.09(0.91-1.30)$ & - \\
\hline Indian & $1.16(0.95-1.42)$ & - \\
\hline Others & $1.01(0.59-1.74)$ & - \\
\hline BMI & $1.02(1.00-1.04)$ & - \\
\hline \multicolumn{3}{|l|}{ Smoking status } \\
\hline Current & 1.00 (reference) & - \\
\hline Ex-smoker & $1.31(1.06-1.63)$ & - \\
\hline Never & $1.54(1.32-1.80)$ & - \\
\hline \multicolumn{3}{|l|}{ Past medical history } \\
\hline Hypertension & $1.26(1.09-1.45)$ & - \\
\hline Diabetes mellitus & $1.20(1.04-1.39)$ & - \\
\hline Dyslipidemia & $1.07(0.93-1.23)$ & - \\
\hline $\mathrm{AMI} / \mathrm{CABG} / \mathrm{PCl}$ & $1.26(1.01-1.56)$ & - \\
\hline EMS utilization & $0.47(0.41-0.54)$ & $0.46(0.39-0.53)$ \\
\hline \multicolumn{3}{|l|}{ ECG diagnosis } \\
\hline Anterior & $1.01(0.88-1.16)$ & $0.54(0.35-0.84)$ \\
\hline Posterior & $0.85(0.70-1.04)$ & - \\
\hline Inferior & $0.90(0.79-1.04)$ & $0.56(0.36-0.86)$ \\
\hline Lateral & $1.15(0.99-1.33)$ & - \\
\hline LBBB & Not applicable* & - \\
\hline Right ventricular & $0.62(0.47-0.81)$ & $0.65(0.48-0.87)$ \\
\hline Creatinine & $1.04(1.02-1.05)$ & $1.03(1.01-1.05)$ \\
\hline Hemoglobin & $0.93(0.90-0.97)$ & - \\
\hline \multicolumn{3}{|l|}{ Killip score } \\
\hline Class 1 & 1.00 (reference) & 1.00 (reference) \\
\hline Class 2 & $1.53(1.07-2.18)$ & $1.34(0.93-1.93)$ \\
\hline Class 3 & $5.28(2.99-9.34)$ & $3.73(2.07-6.72)$ \\
\hline Class 4 & $1.75(1.29-2.38)$ & $1.61(1.17-2.24)$ \\
\hline
\end{tabular}

AMI: Acute myocardial infarction; BMI: Body mass index; CABG: Coronary artery bypass grafting; $\mathrm{Cl}$ : Confidence interval; ECG: Electrocardiogram; LBBB: Left bundle branch block; OR: 
Odds ratio; $\mathrm{PCl}$ : Percutaneous coronary intervention; STEMI: ST-elevation myocardial infarction.

* All cases with door-to-balloon time within 60 minutes did not have LBBB. 